\begin{tabular}{c|c|c} 
ISSN 2525-4812 (versão online) & Recebido em: 31/4/2020 & Revista Terceira \\
ISSN 2238-7641 (versão impressa) & Aprovado para Sober 2020: 23/7/2020 & Margem Amazônia \\
http://www.revistaterceiramargem.com/ & Aceito para RTMA: 25/5/2021 & Pán \\
index.php/terceiramargem/index & Período de publicação: jan./jul. 2021 & (v. 7 • n. 17 • Jan./Jun. 2021) \\
\hline
\end{tabular}

Como citar o artigo:

CAMPOS, K. da C. F; SILVA, R. A. Regularização fundiária do DAS: um estudo de caso que evidencia a necessidade de desburocratização das questões agrárias. Revista Terceira Margem Amazônia, v. 7, n. 17, p. 243-251, 2021. DOI: http://dx.doi. org/10.36882/2525-4812.2021v7i17.p243-251

\title{
REGULARIZAÇÃO FUNDIÁRIA DO DISTRITO AGROPECUÁRIO DA SUFRAMA: UM ESTUDO DE CASO QUE EVIDENCIA A NECESSIDADE DE DESBUROCRATIZAÇÃO DAS QUESTÕES AGRÁRIAS
}

Kamila da Costa Fraxe Campos ${ }^{1}$

Rubens Alves da Silva ${ }^{2}$

\begin{abstract}
Resumo: O desenvolvimento sustentável (DS) é um instrumento analítico que pode ser observado na compreensão do Distrito Agropecuário da Suframa (DAS), sobretudo na construção de políticas públicas. É por meio desses constructos que se materializam as questões fundiárias, socioeconômicas e ambientais. Nesse sentido, o objetivo deste artigo foi analisar esses aspectos, sob o prisma de um estudo de caso e suas implicações. Para atingir esse objetivo foram realizados levantamentos de dados e da legislação vigente sobre um caso específico no estado do Amazonas, com vistas a construir um arcabouço teórico-científico profícuo da temática trabalhada. Pode-se inferir, após a análise dos dados, que, apesar da existência de uma ampla legislação, há lacunas que precisam ser preenchidas para que haja avanços significativos no que se refere aos objetivos do DAS.
\end{abstract}

Palavras-chave: Distrito Agropecuário da Suframa, desenvolvimento sustentável, regularização fundiária, desburocratização.

\section{FUNDIAL REGULARIZATION OF AGRICULTURAL DISTRICT OS SUFRAMA: A CASE STUDY THAT EVIDENCES THE NEED FOR DEBUROCRATIZATION OF AGRICULTURAL ISSUES}

\footnotetext{
Abstract: Sustainable development (SD) is an analytical instrument that can be observed in the understanding of the Agricultural District of Suframa (DAS), especially in the construction of public policies. It is through these constructs that land, socioeconomic and environmental issues materialize. In this sense, the objective of this article was to analyze these aspects, from the perspective of a case study and its implications. In order to achieve this objective, surveys of data and of the legislation in force on a specific case in

Administradora, Graduanda em Direito pela Faculdade Luterana do Brasil (Ulbra). Manaus, AM.

E-mail: kamilafraxe@gmail.com

(D) https://orcid.org/0000-0002-5532-3734

2 Advogado, mestre em Direito, professor da Centro Universitário Luterano de Manaus (CEULM/Ulbra) Manaus, AM.

E-mail: rubens@rubensalves.com

(D) https://orcid.org/0000-0003-2491-4088
} 
the State of Amazonas were carried out, with a view to building a fruitful theoretical-scientific framework of the theme worked on. It can be inferred, after analyzing the data, that despite the existence of ample legislation, there are gaps that need to be filled in order for there to be significant advances with regard to the objectives of the DAS.

Keywords: Suframa agricultural district, sustainable development, land regularization, deburocratization.

\section{Introdução}

Vivemos no Brasil do séc. XXI, onde a terra, a saúde, a educação, o meio ambiente e o desenvolvimento sustentável padecem de concretização, não obstante o decrescimento do modelo em face das políticas públicas direcionadas, o qual é continuamente registrado em documentos oficiais. Após a criação do modelo Zona Franca, que foi balizado em três pilares: o industrial, o comercial e o agropecuário, conforme mostra Barbosa (2017, p. 2), "como centro industrial, comercial e agropecuário, a ZFM está estruturada com um distrito industrial desde 1967 e apresentou 490 empresas em funcionamento em dezembro de 2014”. Pela análise temporal, constata-se que a estruturação industrial se deu no mesmo ano de criação da ZFM, pelo Decreto-Lei ${ }^{\circ}$ 288/67 (BRASIL, 1967).

De acordo com Barbosa (2017, p. 2-3), “o Distrito Agropecuário da Suframa (DAS) foi implantado dentro da ZFM em 1976, após o Governo do Estado do Amazonas ter doado área de terreno de 5.893,34 km à Superintendência da Zona Franca de Manaus". Seguindo com a análise temporal, verifica-se que o DAS só foi implantado 9 anos após a sua criação pelo Decreto-Lei $n^{\circ}$ 288/67, mostrando, assim, o direcionamento ao modelo que até hoje prevalece.

O DAS tem como objetivo geral incentivar a produção agropecuária na área delimitada entre os municípios de Manaus, Rio Preto da Eva e Itacoatiara. De acordo com a Suframa (2020b), a atividade agropecuária desempenhada nessa região é a "produção, o processamento e a comercialização dos produtos, subprodutos e derivados, serviços e insumos agrícolas, pecuários, pesqueiros e florestais, inclusive do extrativismo vegetal".

O atual modelo de desenvolvimento sustentável imperativo no estado do Amazonas, a ZFM, segundo resultados oficiais de 2019 (SUFRAMA, 2020d), faturou 104,62 bilhões, tendo como predominância as atividades industriais. Dados do Amazonas (2019) apontam que, no quarto trimestre de 2019, a matriz agropecuária teve um crescimento de 9,21\%, enquanto a indústria cresceu 5,24\%. Muito embora o crescimento da indústria tenha sido menor, ele corresponde numericamente a quatro vezes o valor do agropecuário, que foi de 1.942 milhões, e o industrial foi de 7.939 .

Segundo números obtidos pelo IBGE (2020b), o Produto Interno Bruno (PIB) dos municípios do estado do Amazonas na atividade agropecuária indica que a capital do estado ocupa a quinta colocação; enquanto na indústria Manaus figura na primeira colocação, reflexo de que a atividade industrial não só é predominante no que diz respeito a valores que geram para o estado, mas também na construção das políticas públicas e atenção dos poderes públicos.

Ainda, analisando o Índice de Desenvolvimento Humano (IDH) 2010 (IBGE, 2020a) no quesito economia, o Amazonas figura na $18^{\mathrm{a}}$ posição, enquanto seus municípios mostram que o 
valor adicionado bruto a preços correntes é predominante numericamente na capital. O fato é que vivemos no séc. XXI, época em que territorialmente o maior estado da federação, com o maior potencial de sociobiodiversidade do planeta, ainda é dependente de uma única matriz econômica, que é o Polo Industrial de Manaus (PIM).

Desse modo, a abordagem de temas que tratam do desenvolvimento sustentável necessita passar por uma reflexão, de maneira a ressignificar o DAS enquanto elemento circunstancial ao desenvolvimento de uma nova matriz econômica que respeite o meio ambiente em seu sentido macro. De acordo com Rivas (2014, p. 24), "a economia tem contribuições muito importantes para se chegar a soluções para os problemas ambientais e de recursos naturais". O que corrobora o entendimento de que as atividades econômicas de uma região têm impacto direto no meio ambiente.

Para que se atinja o objetivo pretendido com a criação do DAS é imprescindível que se observe o objetivo de sua criação, que, segundo Suframa (2020c), é:

promover o desenvolvimento de municípios que são fronteiras internacionais na Amazônia e integrá-los ao restante do país, por meio da extensão de alguns benefícios fiscais do modelo ZFM, da melhoria na fiscalização de entrada e saída de mercadorias e do fortalecimento do setor comercial, agroindustrial e extrativo. (SUFRAMA, 2020c, Grifo nosso).

Assim, o modelo de DS implantado buscou, por meio de incentivos fiscais e extrafiscais, diminuir as desvantagens locacionais e proporcionar condições reais de desenvolvimento da região.

Ao mesmo tempo em que o modelo desenvolveu a região, tornou-se a matriz econômica predominante, em que os potenciais da Amazônia foram desconsiderados e nada desenvolvidos. Como afirma Fraxe (2018, p. 17), "desenvolvimento sustentável e evidenciando como paradoxo do desenvolvimento a redução do desmatamento no âmbito do estado do Amazonas, trabalhando a ideia de lucrar com a floresta em pé". Questão que ficou em voga em 2020, dadas as constantes ameaças de não prorrogação dos benefícios, fazendo com que hoje se fale no desenvolvimento sustentável utilizando a floresta como ativo econômico, e não mais como empecilho ao desenvolvimento, a exemplo do distrito bioagroindustrial da Amazônia.

Ainda em Fraxe (2018, p. 23):

O significado de Desenvolvimento Sustentável é algo indefinido na academia. Tornouse um campo de disputa, como, por exemplo, no sentido utilizado por Bourdieu com múltiplos discursos que ora se opõem, ora se complementam. O domínio da polissemia é a expressão maior desse campo de forças, que passa a condicionar posições e medidas de governos, empresários, políticos, movimentos sociais e organismos multilaterais.

Abstrai-se, portanto, a necessidade de observância dos aspectos ambientais e suas implicações dentro do contexto do DS e os processos negociais entre os atores integrantes do DAS.

A visão dos atores sobre o DAS e suas implicações práticas parte da interação de cada produtor rural com os órgãos integrantes das administrações públicas das três esferas de poder. 
O distrito agropecuário ocupa uma área de 589.334 ha, com aproximadamente 1.534 lotes com famílias assentadas, com 970 lotes ocupados, dos quais 506 estão regularizados e 200 em fase de regularização. Daí, pode-se extrair dos dados da Suframa (2020a) que as interlocuções estão caminhando de forma morosa, burocrática e pouco eficiente, privilegiando apenas os grandes produtores, que por sua natureza teriam maiores condições de arcar com esse custo.

No contexto desses princípios e valores, a pesquisa identificou o processo $\mathrm{n}^{\mathrm{o}} 1008436$ 02.2019.4.01.3200 (BRASIL, 2020), em tramitação na 1 a Vara Federal do Amazonas, que trata de um pedido de reintegração de posse, formulado pela Suframa, a partir da ocupação indevida por cerca de 70 famílias, que construíram moradia e plantação em área pertencente ao DAS sem o preenchimento formal dos requisitos. A área teria sido abandonada por empresa privada que no passado recebeu da Suframa as autorizações para ocupação e desenvolvimento de projeto específico.

Fixados tais paradigmas que envolvem a relação dos sujeitos integrantes do DAS com a estrutura governamental, faremos breve análise sobre os fatos, diante de leis e normas constitucionais que fundamentam sua existência, bem como sua necessidade de desburocratização dos requisitos para ocupação e produção em área do DAS.

\section{Capítulo 1 - Um processo judicial revelando questão fundiária relacionada à Área do Distrito Agropecuário da Suframa (DAS)}

O processo judicial alvo da pesquisa é público e de acesso a qualquer pessoa, razão pela qual não encontramos óbice à sua análise.

A Suframa solicitou ao poder judiciário medidas necessárias para reintegração de posse, inclusive com pedido de tutela de urgência, de uma área que alega ser de sua propriedade.

O imóvel pertencente à Suframa está registrado no Cartório do $3^{\circ}$ Ofício de Registro de Imóveis de Manaus, sob a matrícula 407, situado na Rodovia Estadual AM-010, Km 97 a 99 , Ramal Bons Amigos 1, 2 e 3, o qual, segundo vistoria técnica da autarquia federal, foi indevidamente ocupado por inúmeros invasores, conforme documentos que acompanham a petição inicial do referido processo.

A pesquisa identificou relatório de vistoria técnica, bem como relatório fotográfico da ocupação e imagem de satélite da área invadida. Durante a realização das vistorias na área, solicitadas pelas empresas Yuricam Frutamazônica Ltda. e Fink \& Cia. Ltda., para regularização, observou-se que essas empresas abandonaram completamente a área ocupada, a ponto de as construções existentes serem tomadas por invasores.

Neste sentido, o processo de regularização de Yuricam Frutamazônica Ltda. e Fink \& Cia. Ltda. foi, após as recentes vistorias, indeferido e arquivado, uma vez que não mais existia por elas nenhum tipo de ocupação.

Durante a pesquisa processual, concluímos que, se o procedimento de vistorias pela Suframa tivesse sido adotado em tempo e modo, com redestinação do imóvel para implantação de atividades agropecuárias, o imóvel não teria sido completamente invadido. 
O processo teve início em nome de Fink \& Cia. Ltda. e posteriormente passou a ser tramitado em nome de Yuricam Frutamazônica Ltda., sem qualquer autorização do primeiro interessado, e sem que a coordenação do DAS tivesse atentado para esse fato, tendo a empresa Fink \& Cia. Ltda. emitido documentos informando que Yuricam Frutamazônica Ltda. não tinha autorização para tramitar o processo.

Devido ao abandono da área pela empresa, ocorreram diversas invasões nas margens esquerda e direita da Rodovia Estadual AM-010, e foram abertos outros ramais dentro da área, os quais denominados pelos invasores de Ramal Bons Amigos 1, 2 e 3, resultando nas ocupações irregulares descritas no relatório.

Foi possível observar que o patrimônio da Suframa, na área alvo da pesquisa, vem sofrendo diversos danos, principalmente os ambientais, referentes a desmatamentos irregulares, exploração de carvão, exploração ilegal de madeira, dentre outros.

Tendo em vista que as ações de vistoria e regulamentação da área pela Suframa não tiveram trâmite ágil, ocorreu a intensificação de invasões em período recente (2018-2019), razão pela qual a autarquia federal se viu obrigada a tomar medidas urgentes para que fossem cessados os movimentos de invasão que vêm ocorrendo naquela região.

Por meio de comparação entre imagem de satélite datada de 13/8/2014 (0483934) e imagem datada de 19/3/2019 (0483952), existentes no processo, foi possível identificar ainda a supressão vegetal ocorrida na área invadida nesse período.

De acordo com as conclusões da Suframa e suas argumentações no processo estudado, os relatórios anexados como provas das ocupações descritas visam a demonstrar que os supostos invasores não cumprem os requisitos estabelecidos pela Lei no 11.952/2009 (BRASIL, 2009) para serem regularizadas, visto que em grande parte se trata de invasões ocorridas em período recente, durante os anos de 2013 a 2019, o que não está de acordo com o requisito estabelecido no inciso IV do art. $5^{\circ}$.

De acordo com Brasil (2009, art. 5º, para regularização da ocupação, nos termos da lei, o ocupante e seu cônjuge ou companheiro deverão atender os seguintes requisitos:

“... IV - comprovar o exercício de ocupação e exploração direta, mansa e pacífica, por si ou por seus antecessores, anterior a 22 de julho de 2008 ".

Também é importante salientar que, segundo a Suframa, a maioria das ocupações não possui produção agrícola efetiva, o que vem a contrariar o inciso IV do art. $5^{\circ}$, da Lei n ${ }^{\circ}$ 11.952/2009 (para regularização da ocupação, nos termos desta Lei, o ocupante e seu cônjuge ou companheiro deverão atender os seguintes requisitos: “... III - praticar cultura efetiva” (BRASIL, 2020).

Não foram objetos de vistoria pela Suframa os lotes ocupados nos ramais Jangada 2, Sucuriju, Cascavel e do Antigo Traçado da AM-010, pois a maioria das ocupações existentes nesses ramais é anterior a 2008 e possui produção agrícola, possibilitando a realização de regularização fundiária dos ocupantes com a Lei no 11.952/2009, o que depende da regulamentação da lei, em trâmite no processo 52710.001633/2015-17. Por esse motivo, em 11/12/2017, por meio do Despacho $n^{\circ} 0131629$ à coordenação do DAS, denominado CGPAG, achou-se prudente que 
se aguardasse a regulamentação da Lei ${ }^{0}$ 11.952/2009 antes de propor quaisquer medidas de reintegração de posse sobre o imóvel (ramais Jangada 2, Sucuriju, Cascavel e do Antigo Traçado da AM-010).

Figura 1. Imagem topográfica das áreas invadidas.

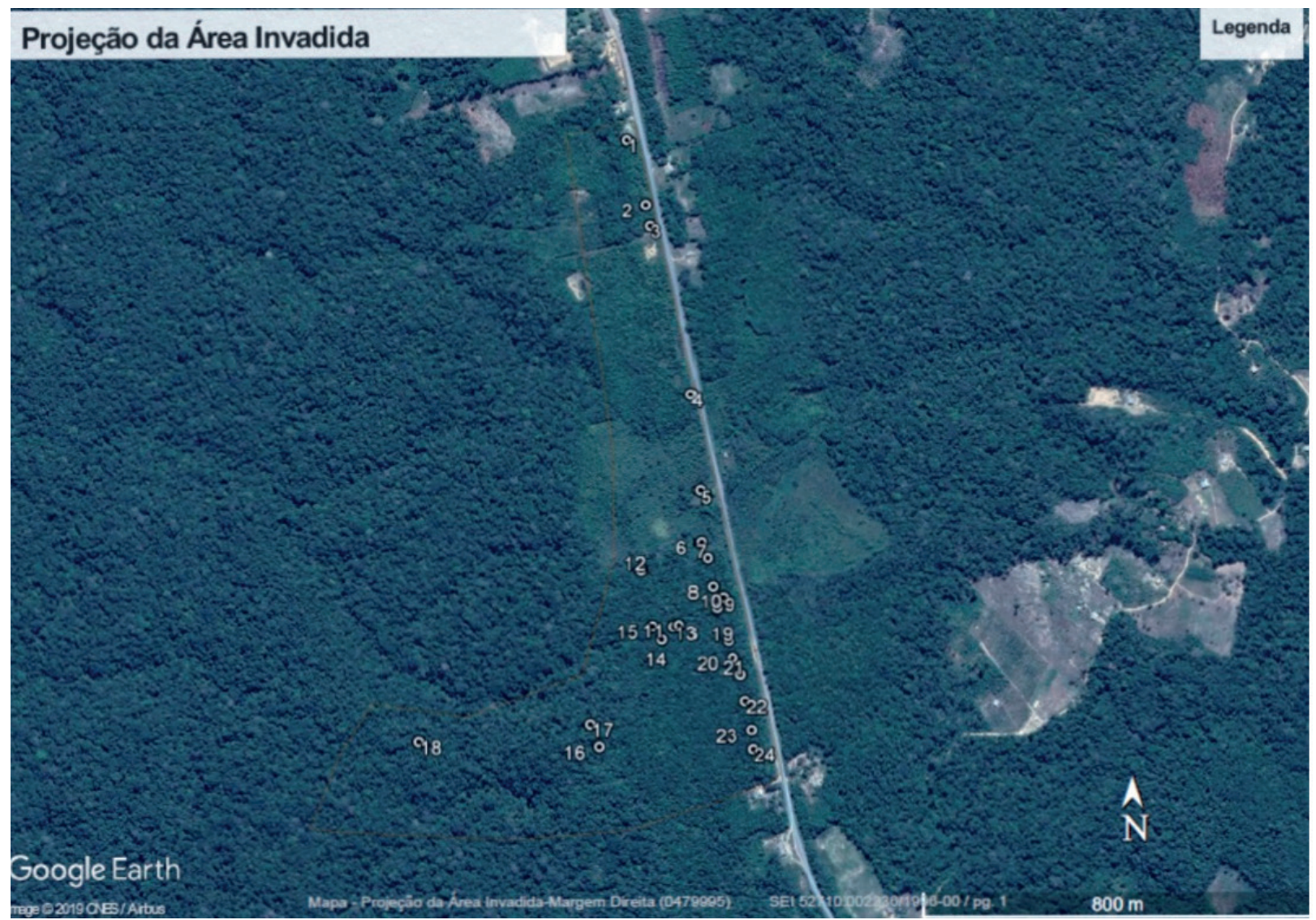

Fonte: Petição Inicial do Processo Judicial n 1008436-02.2019.4.01.3200.

\section{Capítulo 2 - A defesa dos ocupantes}

Os ocupantes, acusados pela Suframa de invasores, tiveram a sua defesa feita pela Defensoria Pública da União, haja vista se tratar de pessoas sem renda fixa e em condição de vulnerabilidade social.

Alegaram durante a audiência, em sua maioria, que trabalhavam para a família dos fazendeiros que abandonaram a área e já residiam na localidade, tendo apenas dado seguimento à exploração da aérea para fins agropecuários quando o "patrão" faleceu e seus filhos foram morar no exterior.

A defensoria alegou no processo, de acordo com a documentação anexada, que, diferentemente do que foi afirmado pela Suframa em seu relatório de vistoria, na quase totalidade das ocupações há plantio de mais de um gênero alimentício ou a criação de pescado, a demonstrar a natureza agrícola da comunidade (BRASIL, 2020). 
A pesquisa destacou a tese segundo a qual, de todas as ocupações, apenas quatro foram iniciadas em 2019 e não caracterizam posse antiga. As demais contam com pelo menos 2 anos e chegam a até 23 (ocupação $n^{\circ} 63$ ), muitas delas preenchendo os requisitos para a regularização fundiária prevista na Lei no 13.465/17 (BRASIL, 2017), bastando a atuação da Prefeitura de Rio Preto da Eva para permitir a regularização fundiária.

A pesquisa também identificou que várias ocupações tiveram a chancela de certidões expedidas pela Prefeitura de Rio Preto da Eva declarando e, ao mesmo tempo, autorizando a ocupação. Muito embora, caso se reconheça a efetiva propriedade da Suframa sobre a área, tais certidões não possam ser opostas à real proprietária, são suficientes para legitimar a posse dos ocupantes. A uma, por fazê-los crer serem portadores de justo título de posse. A duas, por, consequentemente, evidenciarem a boa-fé das famílias residentes.

De acordo com a defesa feita pela Defensoria Pública da União (DPU), percebe-se a legitimidade da ocupação pelo fato de os ocupantes terem logrado a inscrição do imóvel no Cadastro Ambiental Rural (CAR), o que somente ocorreu em razão da existência de documentos que, conquanto possam ser contestados pela proprietária, fazem crer a qualquer pessoa haver regularidade na posse a qual se referem.

Exemplificativamente, conforme identificado no processo, encontramos o exemplo do ocupante do lote $n^{\circ} 45$. Como se observa na documentação que se apresenta, a ocupação data de janeiro de 2017, caracteriza-se pela prática de agricultura familiar, dispõe de certidão expedida pela Prefeitura de Rio Preto da Eva e de inscrição no CAR.

\section{Conclusão}

Como se sabe, a posse é um "estado de fato" protegida pelo Direito Civil, cujo diploma material, em seu art. 1.228, assegura ao proprietário "o direito de usar, gozar e dispor de seus bens, e de reavê-los do poder de quem quer que injustamente os possua” (BRASIL, 2002).

No processo alvo da pesquisa, a Suframa se utiliza de um instrumento do direito civil, a posse, para tentar reaver os direitos possessórios sobre uma área de sua propriedade.

De fato e de direito, às ações possessórias destinadas à proteção do patrimônio público aplica-se o art. 71 do Decreto-Lei n ${ }^{\circ}$ 9.760/46 (BRASIL, 1946): "O ocupante de imóvel da União, sem assentimento desta, poderá ser sumariamente despejado e perderá, sem direito a qualquer indenização, tudo quanto haja incorporado ao solo, ficando ainda sujeito ao disposto nos arts. 513, 515 e 517 do Código Civil (BRASIL, 2002).

De acordo com as peças processuais e provas analisadas, observou-se que a omissão da Suframa por alguns anos, sem que tivesse atentado para as vistorias na área, foi um dos fatores que favoreceram a ocupação por pessoas sem vínculo formal com os processos de utilização das áreas do DAS.

Com o passar dos anos, as pessoas ergueram moradias de madeira e concreto, passaram a criar espécies como galinhas, patos e até algum gado, além de fazer plantações de frutas e roçados, tornando, a cada dia, mais difícil a sua retirada do local. Algumas famílias receberam auto- 
rização de ocupação. Sobre outras recaem dificuldades de ordem burocrática, como ausência de documentos mínimos para tramitação de seus pedidos de regularização fundiária.

Após audiência de tentativa de conciliação, em razão de fatos supervenientes, como a pandemia da covid-19 que assola o planeta, levando as autoridades públicas a decretarem estado de calamidade, determinou-se, no processo, que não haveria reintegração de posse durante a pandemia, como forma de cumprir as determinações da Organização Mundial de Saúde (OMS) e as resoluções do CNJ sobre o tema, especialmente a 62.

Desse modo, ainda permanece uma indefinição sobre como ficará a ocupação da área pelas cerca de 70 famílias acusadas de invasoras.

Por fim, considerando que há presente o requisito da boa-fé na ocupação e que a maior parte das famílias desenvolve plantio, pescado e criações na forma da lei, também pelo fato de que até a presente data a justiça não determinou a desocupação das famílias, os indicadores apontam pela regularização fundiária da área, de acordo com os objetivos do DAS.

\section{Referências}

AMAZONAS. Secretaria de Planejamento, Desenvolvimento, Ciência, Tecnologia e Inovação. Produto interno bruto trimestral $-4^{\circ}$ trimestre 2019. Manaus, 2019. Disponível em: http://www.sedecti.am.gov. br/wp-content/uploads/2020/03/PIB_4_Trimestral_2019.pdf. Acesso em: 30 mar. 2020.

BARBOSA, E. B. Distrito Agropecuário da Suframa (DAS): gênese, desenvolvimento e dilemas para o século XXI. 2017. 229 f. Tese (Doutorado em Ciências do Ambiente e Sustentabilidade na Amazônia) Universidade Federal do Amazonas, Manaus.

BRASIL. Congresso Nacional. Código Civil Brasileiro - Lei n 10.406/02. Brasília, DF, 2002.

BRASIL. Congresso Nacional. Decreto-Lei de Regulamentação da Zona Franca de Manaus - DecretoLei $\mathbf{n}^{\circ}$ 288/67. Brasília, DF, 1967.

BRASIL. Congresso Nacional. Decreto-Lei dos Bens Imóveis da União - Decreto-Lei $n^{\circ}$ 9.760/46. Brasília, DF, 1946.

BRASIL. Justiça Federal. Reintegração de Posse n 1008436-02.2019.4.01.3200. Disponível em: https:// pje1g.trf1.jus.br/consultapublica/ConsultaPublica/DetalheProcessoConsultaPublica/listView.seam?ca=caee3584e29a3651afe1000db5f977e499009654a1964999. Acesso em: 1 abr. 2020.

BRASIL. Congresso Nacional. Lei de Regularização Fundiária das ocupações incidentes em terras da União, no âmbito da Amazônia Legal - Lei n 11.952/09. Brasília, DF, 2009.

BRASIL. Congresso Nacional. Lei de Regularização Fundiária Rural e Urbana, sobre a liquidação de créditos concedidos aos assentados da reforma agrária e sobre a regularização fundiária na Amazônia Legal - Lei n 13.465/17. Brasília, DF, 2017.

FRAXE, J. ICMS verde: um instrumento de sustentabilidade ambiental no Amazonas. 2018. 159 f. Dissertação (Mestrado em Ciências do Ambiente e Sustentabilidade na Amazônia) - Universidade Federal do Amazonas, Manaus.

IBGE. Panorama do Estado do Amazonas. Disponível em: https:/cidades.ibge.gov.br/brasil/am/panorama. Acesso em: 30 mar. 2020a. 
IBGE. Produto Interno Bruto do Municípios do Estado do Amazonas. Disponível em: https://cidades. ibge.gov.br/brasil/am/manaus/pesquisa/38/47001?tipo=ranking\&indicador=47007. Acesso em: $30 \mathrm{mar}$. $2020 \mathrm{~b}$.

RIVAS, A. A. Economia e valoração de serviços ambientais utilizando técnicas de preferências declaradas. Manaus: EDUA, 2014.

SUFRAMA. Dados do Distrito Agropecuário da Suframa. http://www.suframa.gov.br/noticias/arquivos/Panorama_do_Distrito_Agropecuário_Suframa.pdf. Disponível em: 2 abr. 2020a.

SUFRAMA. Distrito Agropecuário. Disponível em: https://www.gov.br/suframa/pt-br/assuntos/distrito-agropecuario. Acesso em: 30 mar. 2020b.

SUFRAMA. História do Modelo Zona Franca. Disponível em: https://www.gov.br/suframa/pt-br/zfm/ area-de-beneficios. Acesso em: 30 mar. 2020c.

SUFRAMA. Indústrias do PIM fecham 2019 com faturamento recorde. Disponível em: https://www. gov.br/suframa/pt-br/publicacoes/noticias/faturamento-pim-atinge-marca-inedita-de-r-104-bi-em-2019. Acesso em: 30 mar. 2020d. 
